Reprod. Nutr. Dévelop., 1984, 24 (1), 81-94.

\title{
Motility induction in hamster spermatozoa from caput epididymidis : effects of forward motility protein (FMP) and calmodulin inhibitor
}

\author{
Catherine SERRES, Marie-Louise KANN $\left({ }^{*}\right)(1)$
}

Laboratoire d'Histologie-Embryologie, Centre hospitalier, 78, rue du Généra/-Lec/erc, 94270 Kremlin-Bicêtre, France.

(*) Physiologie de la Reproduction des Vertébrés, Université Pierre et Marie Curie,

4. place Jussieu, 75230 Paris Cedex 05, France.

\begin{abstract}
Summary. The motility characteristics and the behaviour of caput spermatozoa were investigated. After dilution in $\mathrm{B}_{2}$ medium the majority of spermatozoa presented head-tohead agglutination and a twisted flagellum. Only a small population of these spermatozoa developed an anarchic motility pattern. The addition of crude bovine epididymal fluid forward motility protein (FMP) to the incubation medium suppressed flagellar angulation and agglutination. The addition of FMP to caffeine-activated spermatozoa induced a slowswimming progressive movement in about $10 \%$ of the spermatozoa. In order to establish an hypothetical role of FMP in the regulation of calcium transport a calmodulin inhibitor, fluphenazin, was tested. When added to caffeine-activated spermatozoa at a rate of $10^{-5} \mathrm{M}$, it induced about $15 \%$ of progressive spermatozoa with flagellar angulations. The trajectories of these spermatozoa were similar to those observed in samples of spermatozoa from the cauda epididymidis. it is concluded that during epididymal maturation a calciumdependent mechanism might be involved in the transformation of an irregular movement into a progressive movement.
\end{abstract}

\section{Introduction.}

Mammalian spermatozoa acquire forward motility during epididymal maturation. The spermatozoa extruded from the caput epididymidis are rarely motile (Morton, 1978) and the motility pattern observed is very often anarchic. In the hamster, we have previously provided evidence that forward motility is induced in immature spermatozoa by the dual presence of a cyclic nucleotide phosphodiesterase inhibitor, such as 'caffeine, to elevate cAMP levels, and cauda epididymal plasma in the incubation medium (Kann and Serres, 1980). Hoskins et al. (1978) have shown that a protein present in epididymal plasma induces forward motion in washed bovine caput spermatozoa in the presence of

(1) For correspondance and reprints. 
theophylline or other phosphodiesterase inhibitors. The epididymal protein has been called "forward motility protein " (FMP) by Acott and Hoskins (1978). These authors suggested that the protein is involved in the regulation of calcium transport (Hoskins et al., 1983). In the present study, the motility characteristics and behaviour of hamster caput spermatozoa were investigated. Spermatozoa were diluted and incubated with crude bovine FMP in the presence or absence of caffeine. In order to establish an hypothetical role of forward motility protein in the regulation of calcium transport a calmodulin inhibitor was tested upon immature spermatozoa activated by caffeine. This inhibitor, a regulatory protein ubiquitous in eukariotic systems, activates various enzymatic activities in a calcium-dependent manner (Klee et al., 1980).

\section{Material and methods.}

1. Preparation of sperm suspensions. - Mature 2 to 5-month old hamster males were anesthetized with pentobarbital. Undiluted fractions of samples from caput and cauda epididymidis were obtained by micropuncture. Sperm suspensions from each epididymal segment were obtained by cutting the tissue in either $2 \mathrm{ml}$ of normal $B_{2}$ culture medium (Ménézo, 1976) (osmolality: $290 \mathrm{mOsm} / \mathrm{kg}$ ) or $2 \mathrm{ml}$ of hyperosmolar $B_{2}$ medium losmolality : $400 \mathrm{mOsm} / \mathrm{kg}$ by the addition of $\mathrm{NaCl}$ or saccharosel. The preparations were filtered to discard the excess tissue before observation.

2. Induction of motility. - A $0.05 \mathrm{M}$ caffeine solution (Sigma) dissolved in $\mathrm{B}_{2}$ medium was used at $25 \mathrm{mM}$ final concentration. The incubations were carried out at room temperature in the presence of either crude bovine epididymal fluid FMP $(2.5 \mathrm{mg} / \mathrm{ml})$, partially purified through a Sephadex gel (Hoskins, personal communication), or a calmodulin inhibitor (fluphenazin : $10^{-3}$ to $10^{-5} \mathrm{M}$ ( (Coger).

3. Motility observations. - One drop of each sperm suspension was immediately placed on an hemocytometer slide (depth : $0.1 \mathrm{~mm}$ ). The preparations were examined by phase-contrast at ambiant temperature. Photographs were taken under dark-field illumination or interference contrast. Observations were also recorded cinematographically on moving Kodak film by interference contrast with a magnification of $X 140$ and at 24 frames per sec. The films obtained were projected frame by frame. The successive head-neck junction positions of the motile spermatozoa were noted on paper for a period of 2 sec and mean progressive velocity was calculated.

PLATE 1

Dark-field illumination of hamster spermatozoa from the same caput epididymidis.

FIG. 1. - Spermatozoa diluted in normal $B_{2}$ medium.

FIG. 2. - Spermatozoa diluted in normal $B_{2}$ medium with crude bovine FMP added.

The number of twisted and agglutinated spermatozoa incubated in normal $B_{2}$ medium (fig. 1) was decreased greatly after the addition of crude FMP (fig. 2). 

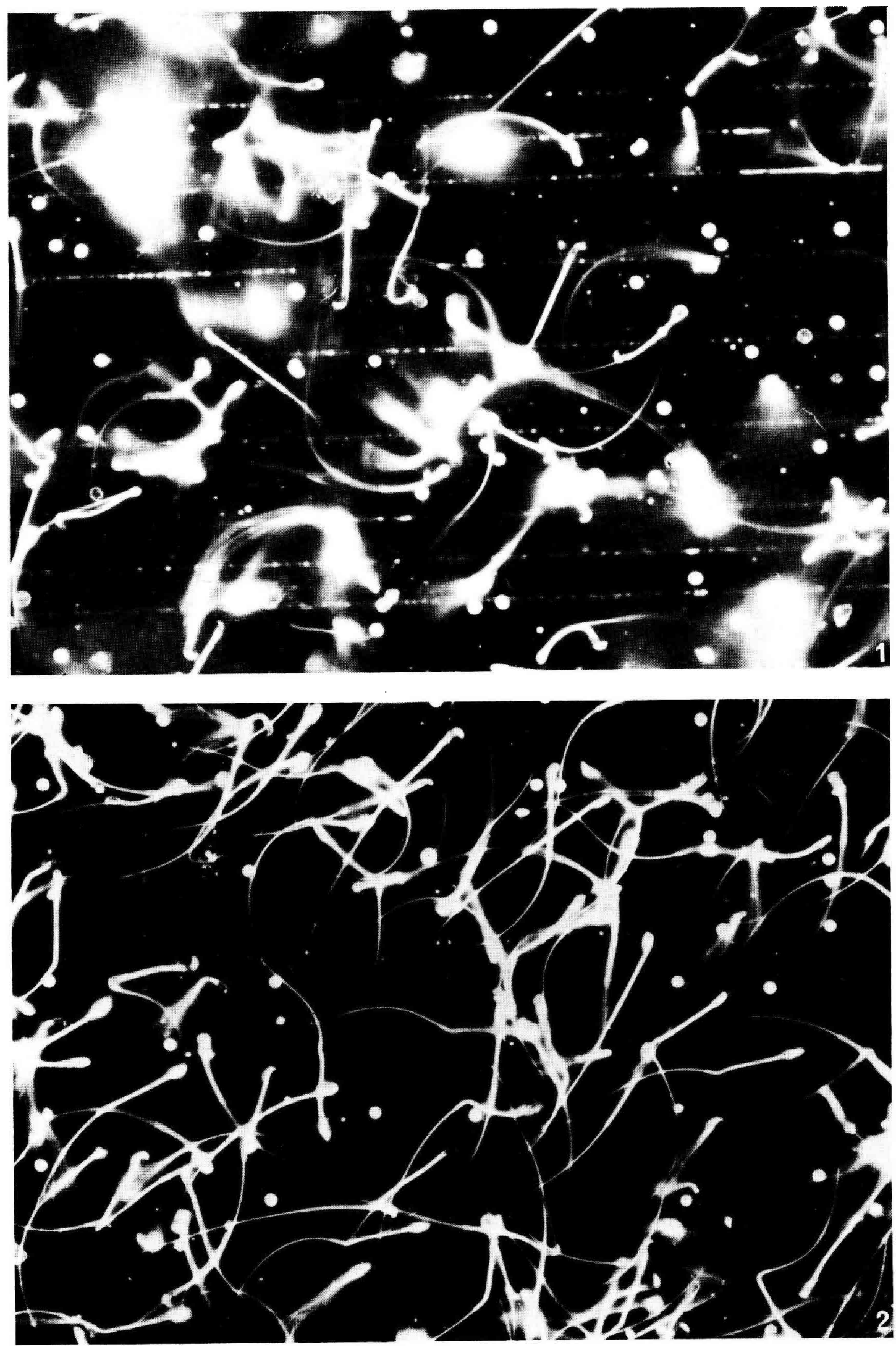
4. In situ observations. - A male hamster was killed by cervical dislocation ; its caput epididymis, collected just after death, was fixed in Bouin Holland's fixative, dehydrated, embedded in paraffin, cut into sections $7-\mu \mathrm{m}$ thick and stained with Masson trichromic staining. The slides were observed under a stereoscopic .microscope at $\times 650$ magnification and photographs were taken when necessary.

5. Osmolarity measurement. - Osmolarity was determined by measuring freezing point depression with a nanoliter osmometer.

\section{Results.}

1. Motility of epididymal sperm : dilution effect.

a) The spermatozoa were observed to be motionless soon after removal without dilution of caput and cauda epididymidis.

b) After dilution in normal $B_{2}$ medium $(290 \mathrm{mOsm} / \mathrm{kg})$ only a small population of spermatozoa from the caput epididymidis developed a slow motility pattern. The great majority of spermatozoa extruded from the cauda epididymidis showed a progressive movement (Pl. Vla), as previously reported by Kann and Serres (1980). Gradually, caput motile spermatozoa showed head-to-head agglutination (PI. I, fig. 1; PI. IV, fig. 1; PI. V, fig. 1); most of these spermatozoa (motile and immotile) presented a bent flagellum (PI. V, fig. 1). Angulation always occurred at the level of the middle piece, sometimes near the neck (PI. II, figs. 1, 2) but more often close to the Jansen ring (PI. II, figs. 3, 4). The angulations presented a variable degree of curvature (PI. V, fig. 1) and were observed in the plane of the hook of the sperm head. At the level of these angulations the plasma membrane appeared detached from the mitochondrial helix (PI. II, fig. 1, 2).

After dilution in a hyperosmolar $\mathrm{B}_{2}$ medium $(400 \mathrm{mOsm} / \mathrm{kg})$, obtained by the addition of $\mathrm{NaCl}$ or saccharose, none of the immature spermatozoa presented an angular flagellum (PI. II, fig. 5 ; PI. III, fig. 2). Flagellar shape was similar to that observed in situ (PI. III, fig. 1).

Spermatozoa from the cauda epididymidis showed neither flagellar angulation nor agglutination with or without dilution.

2. Influence of crude bovine FMP on immature diluted spermatozoa and its effect after caffeine-induced motility.

PLATE II

Interference contrast of spermatozoa from the caput epididymidis.

FIGS. 1-2. - Spermatozoa in norma/ $B_{2}$ medium. Flagellar angulation is observed near the neck. FIGS. 3-4. - Spermatozoa in normal $B_{2}$ medium. Flagellar angulation is close to the Jansen ring. FIG. 5. - Spermatozoa in hyperosmolar $B_{2}$ medium. No flagellar angulation is seen. 

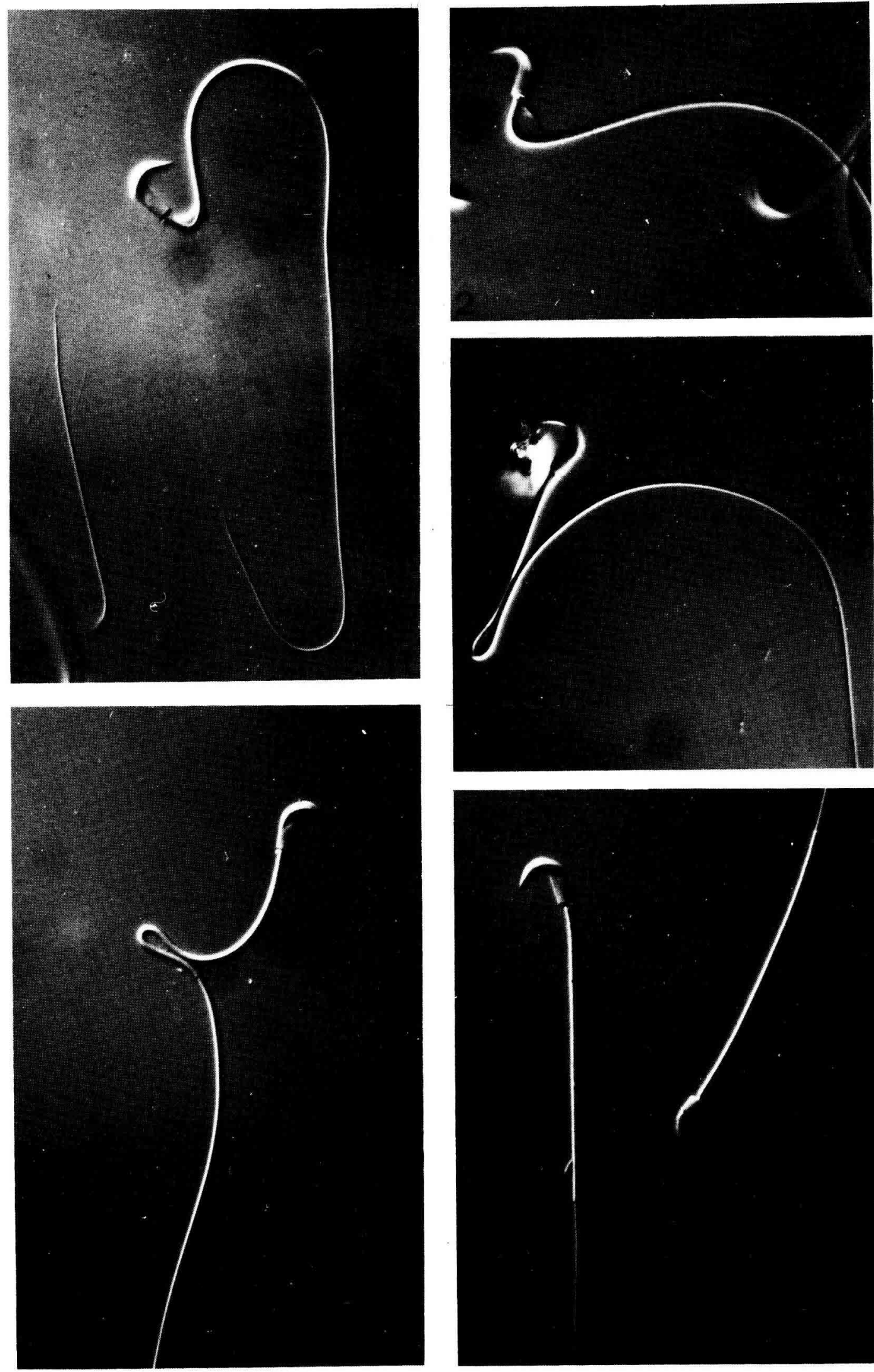
a) The unique presence of crude FMP in the incubation medium containing immature epididymal spermatozoa induced the following changes (results of 7 incubations) :

- the number of twisted spermatozoa was greatly decreased (PI. I, fig. 2). Most of the remaining few flagellar angulations observed were not accentuated (PI. V, fig. 2). The flagella were relaxed similar to those observed in spermatozoa from the cauda epididymidis. These spermatozoa were either immotile or showed slow flagellar beating with no progression; there was no agglutination.

b) Caffeine alone added to normal $B_{2}$ medium induced irregular nonprogressive motility in immature spermatozoa, as described by Kann and Serres (1980), but flagellar angulation and agglutination were comparable to those described above after dilution in normal $\mathrm{B}_{2}$ medium only (PI. IV, figs. 1,2 ).

c) The addition of crude FMP to caffeine-activated spermatozoa induced a slow-swimming progressive movement in about $10 \%$ of the spermatozoa and eliminated agglutination and middle piece angulation (results of 7 incubations) (PI. IV, fig. 3). The addition of crude FMP did not increase the osmotic pressure of the medium $(267 \mathrm{mOsm} / \mathrm{kg})$. Plate VIb shows a plot of the heads of such typical spermatozoa from an incubation where 10 out of the 86 spermatozoa analysed moved progressively with a mean velocity of $46 \pm 15 \mu \mathrm{m} / \mathrm{sec}$; the trajectory patterns were wider and slightly less direct than those of cauda spermatozoa (PI. Vla).

3. Influence of calmodulin inhibitor (fluphenazin) on immature spermatozoa and its effect after caffeine-induced motility.

a) Fluphenazin $\left(10^{-4} \mathrm{M}\right)$ added to normal $B_{2}$ medium did not alter such sperm characteristics as agglutination, angulation and motility pattern (results of 8 incubations).

b) The addition of fluphenazin $\left(10^{-5}\right.$ to $\left.10^{-4} \mathrm{M}\right)$ to caffeine-activated spermatozoa (29 incubations) induced some spermatozoa with flagellar angulation to progress but agglutination was observed. Microcinematographic analysis of 2 incubations showed 13 and $15 \%$, respectively, of progressive spermatozoa. The movements of such spermatozoa after fluphenazin incubation are shown on Plate VIc. Their trajectories were similar to those observed with samples of spermatozoa from the cauda epididymidis and their mean velocity was $72 \pm 18 \mu \mathrm{m} / \mathrm{sec}$ ( $\mathrm{n}=18$ ). A higher concentration of fluphenazin $\left(5 \cdot 10^{-4}\right.$ to $\left.10^{-3} \mathrm{M}\right)$ was detrimental, inducing quick flagellar vibrations without progression, then immobilization of the cells (results of 8 incubations).

FIG. 1. - Spermatozoa of the caput epididymidis from an histological preparation observed in situ.

FIG. 2. - Frame recorded cinematographically by interference contrast of spermatozoa from the caput epididymidis diluted in hyperosmolar $B_{2}$ medium. 

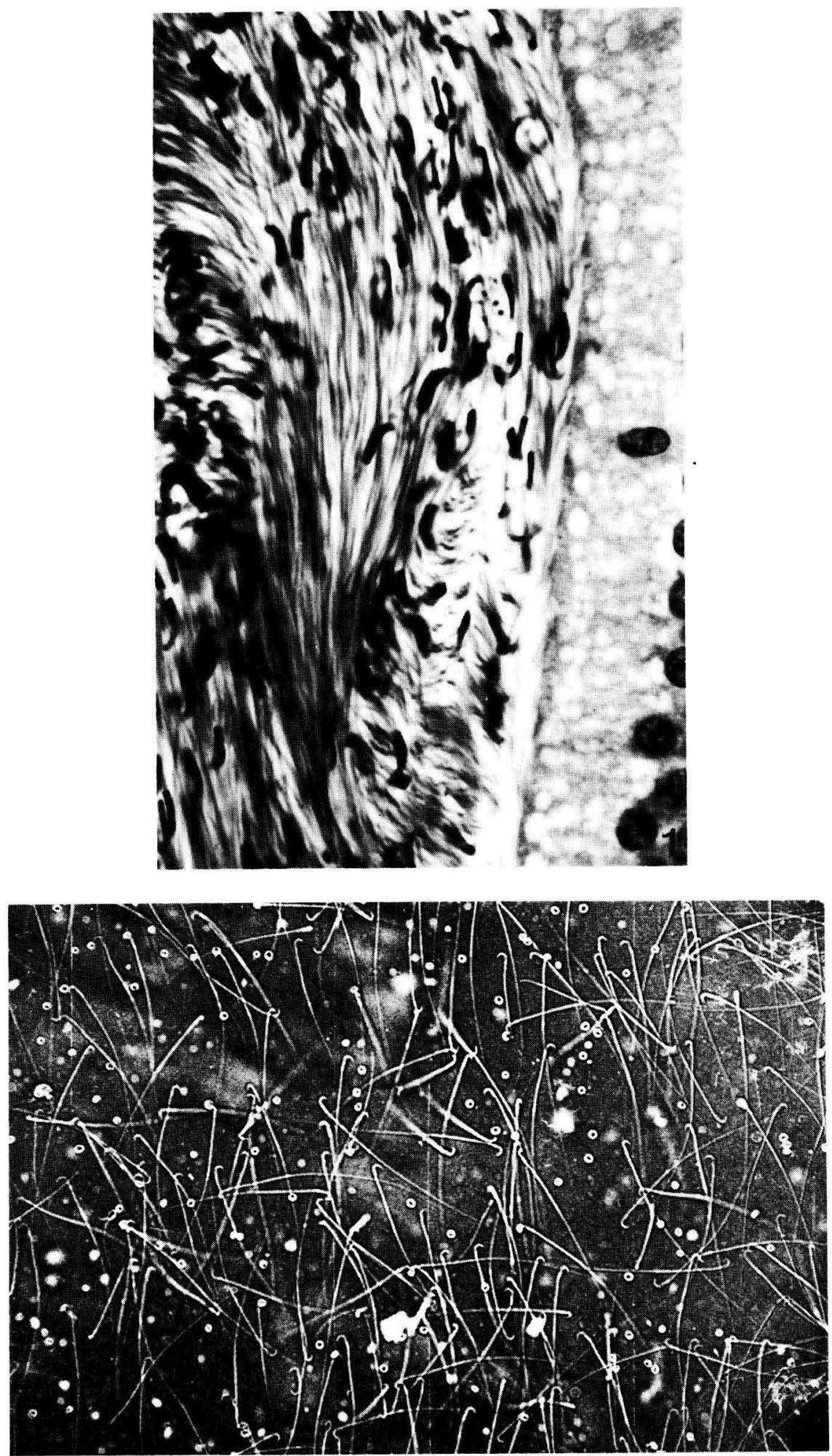


\section{Discussion.}

We observed that immature spermatozoa extruded without dilution from the caput epididymidis were motionless, as reported previously by Morton et al. (1978). The flagella of these spermatozoa were not twisted. After dilution in normal $B_{2}$ medium $(290 \mathrm{mOsm} / \mathrm{kg}$ ) only some of the spermatozoa became motile in a non-progressive manner, confirming the results of a previous study (Kann and Serres, 1980). In the present study, emphasis was put on two other sperm modifications due to dilution : (1) the head-to-head agglutination joining many spermatozoa, and (2) typical flagellar angulation in the middle piece region.

After dilution in hyperosmolar $B_{2}$ medium $(400 \mathrm{mOsm} / \mathrm{kg})$, neither motile nor immotile spermatozoa showed angulation. After dilution in normal or hyperosmolar $\mathrm{B}_{2}$ medium, spermatozoa from the cauda epididymidis became motile with forward progression, showing neither agglutination nor flagellar twisting. So, it is likely that the flagellar twisting observed in the region of the middle piece of immature spermatozoa was due to hypotonic shock since hamster caput epididymal plasma is hyperosmolar $(410 \mathrm{mOsm} / \mathrm{kg}$ ) (Johnson and Howards, 1977). These observations are compatible with the data of Blandau and Rumery (1964), Fray et al. (1972) and Wiker and Howards (1977) who reported that after dilution immature rat spermatozoa from the caput epididymidis showed either a " retroflexion of the head and curvature of the neck region " or a "coma shape ". The absence of flagellar twisting during epididymal transit in spermatozoa from the caudal epididymidis might reflect adaptation to a lower osmotic pressure than that in the caput epididymidis $(340 \mathrm{mOsm} / \mathrm{kg}$ instead of $410 \mathrm{mOsm} / \mathrm{kg}$ ) (Johnson and Howards, 1977), thus adjusting the spermatozoa to hypotonicity.

The head-to-head agglutination of spermatozoa from the caput epididymidis ascertained after dilution in normal $B_{2}$ medium suggests a difference between the cell coat of immature and mature spermatozoa. Therefore, the dilution effect has unmasked events which possibly denote modifications in the permeability and the nature of the cell coat of the sperm plasma membrane during epididymal transit ; these changes have already been demonstrated using other techniques (Hammerstedt et al., 1979 ; Nicolson et al., 1979).

\section{PLATE IV}

Frames recorded cinematographically by interference contrast of spermatozoa from the same caput epididymidis.

FIG. 1. - Spermatozoa after dilution in normal $B_{2}$ medium.

FIG. 2. - Spermatozoa after the addition of caffeine to the normal $B_{2}$ medium.

FIG. 3. - Spermatozoa after addition of crude bovine FMP to the previous caffeine-activated spermatozoa.

The flagellar angulation and agglutination described after dilution in normal $B_{2}$ medium (fig. 1) were still observed after the addition of caffeine (fig. 2). The addition of crude FMP to these caffeineactivated spermatozoa eliminated agglutination and middle piece angulation (fig. 3). 

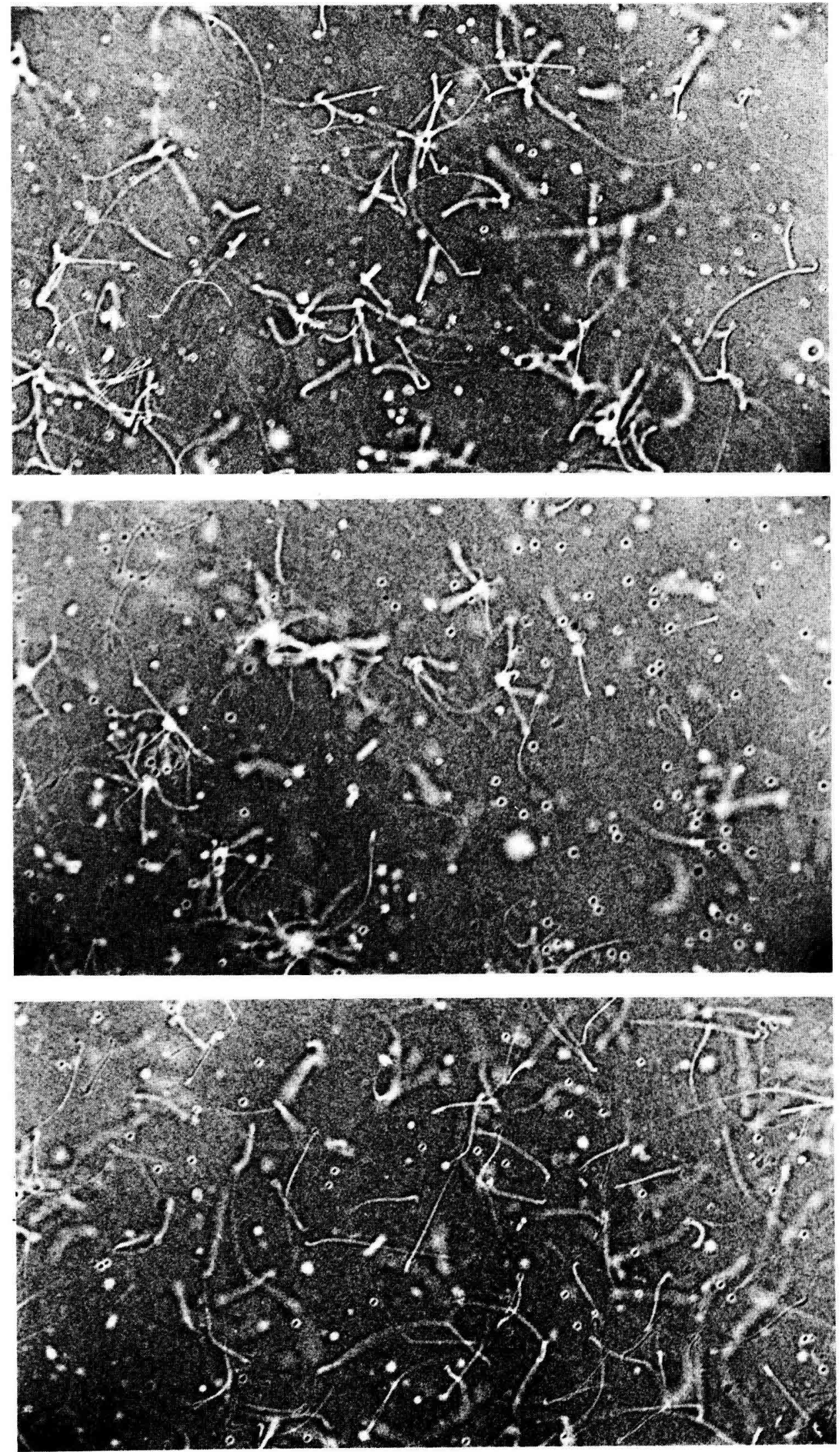
The effect of crude bovine FMP on caput spermatozoa of hamster has been proved in the present study by the spectacular disappearance of agglutination and flagellar twisting when FMP is added to the medium. Dacheux et al. (1983) have also reported recently that spermatozoa from the corpus epididymidis of boars and rams show head-to-head agglutination when diluted and that agglutination is inhibited by the addition of non-species specific plasma of the cauda epididymis. Acott and Hoskins (1981) and Stephens et al. (1981) studying bull noticed that the use of crude fluids, i.e. coating proteins instead of purified FMP, prevented caput spermatozoa from being sticky and aggregating. The absence of agglutination in spermatozoa from the cauda epididymidis might be explained by the binding of coating proteins (antagglutinin, for example : Dacheux et al., 1983) on the surface of the sperm plasma membrane during epididymal transit. Flagellar angulation disappeared when crude bovine FMP was added to non-activated or caffeine-activated caput spermatozoa and the osmotic pressure of the medium was not modified; this shows that the spermatozoa adapted to extracellular hypotonicity by changing the permeability of the plasma membrane in the same manner as during epididymal transit (Hammerstedt et al., 1979).

Immature spermatozoa incubated with crude bovine FMP were immotile. This observation is consistent with the data of Acott and Hoskins (1981) which revealed no motility ( $\mathrm{FMI}=0$ ) in bovine caput spermatozoa exposed to caudal fluid alone. However, an identical addition of FMP to caffeine-activated caput spermatozoa induced slow progressive movement in about $10 \%$ of the population. The addition of partially purified bovine FMP $(0.1 \mathrm{mg} / \mathrm{ml})$ plus caffeine $(50 \mathrm{mM})$ to ram spermatozoa from the proximal corpus epididymidis also induced about $10 \%$ of motile spermatozoa (Amann et al., 1982). This low percentage of motile spermatozoa might be explained by the fact that the crude FMP originated from bovine material, although the incubation of bovine caput spermatozoa with theophylline $33 \mathrm{mM}$ plus bovine crude FMP induced no more than $33 \%$ of progressive spermatozoa (Acott and Hoskins, 1983). Yet, the trajectory patterns of immature activated hamster spermatozoa, induced by crude bovine FMP, were less progressive than those observed with caudal samples. The mechanism by which FMP would change an anarchic movement pattern into a progressive movement pattern is not clear. From results on the development of motility in bull, Hoskins (1982-1983) suspects that the greater $\mathrm{Ca}^{++}$influx in caput spermatozoa, compared to caudal spermatozoa, is responsible for the

\section{PLATE V}

Frames recorded cinematographically by interference contrast of spermatozoa from the caput epididymidis.

FIG. 1. - Spermatozoa after dilution in normal $B_{2}$ medium present flagellar angulation at the level of the middle piece.

FIG. 2. - Spermatozoa after the addition of crude bovine FMP. Most of the remaining few flagellar angulations observed are not accentuated. 

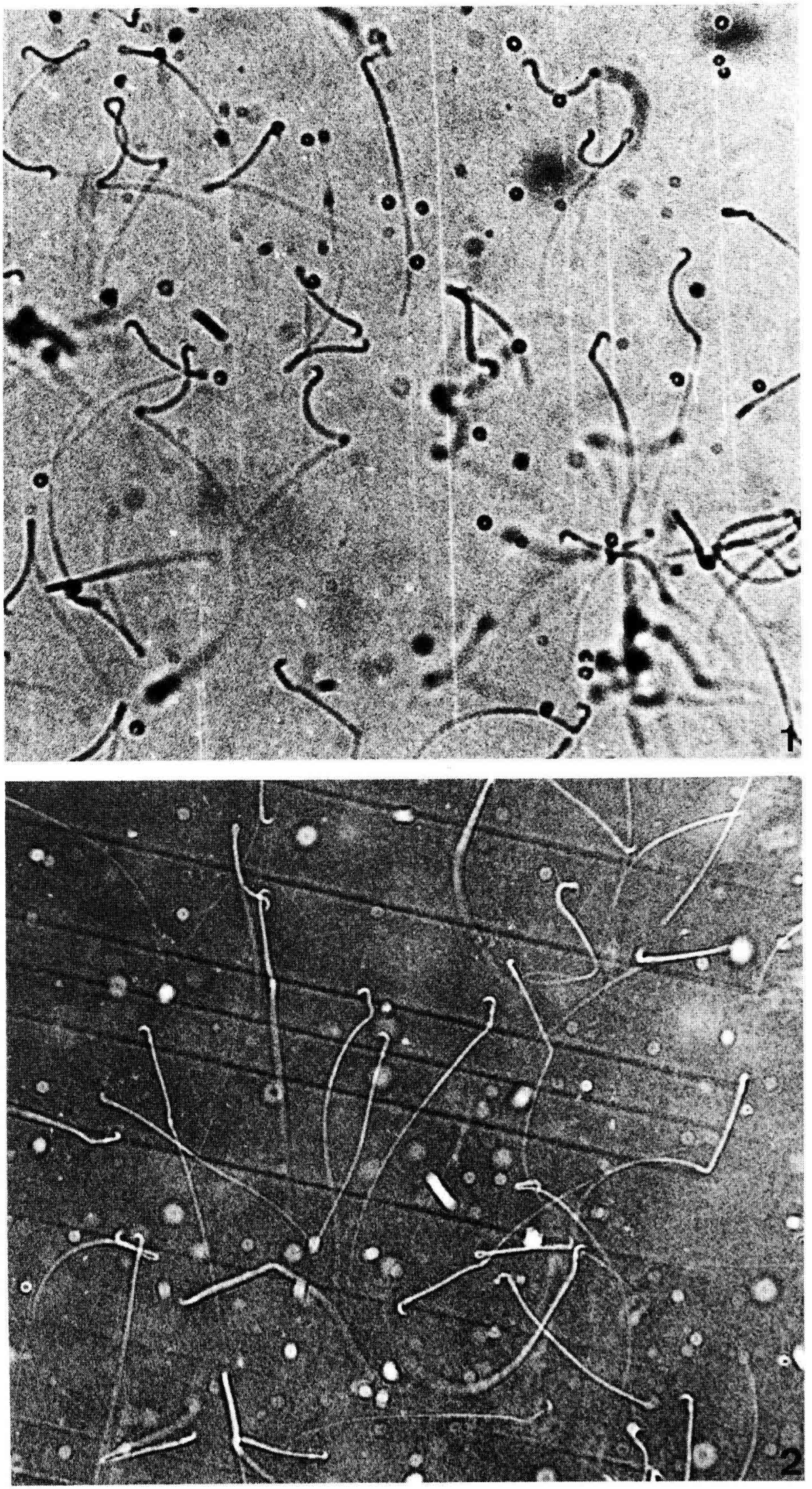
a

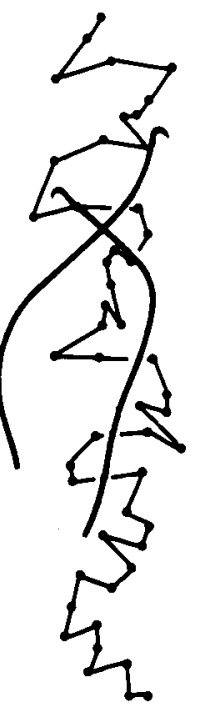

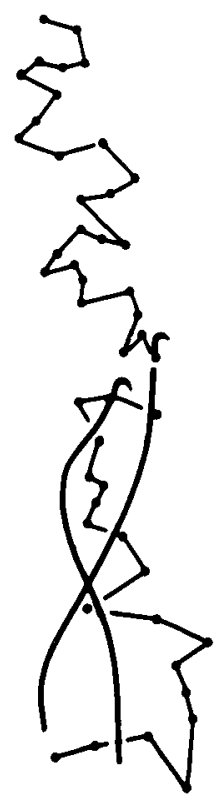

$C$

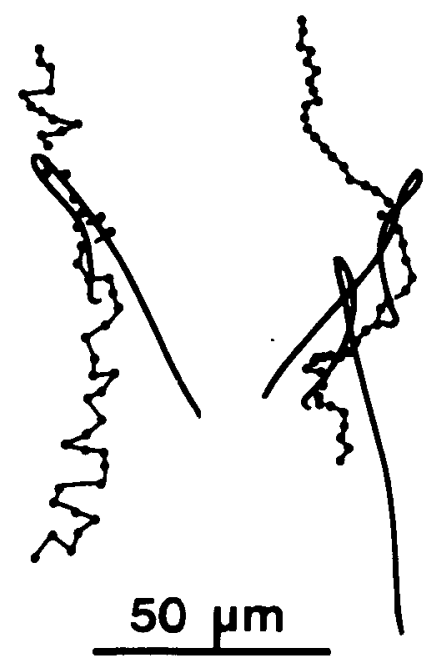

b
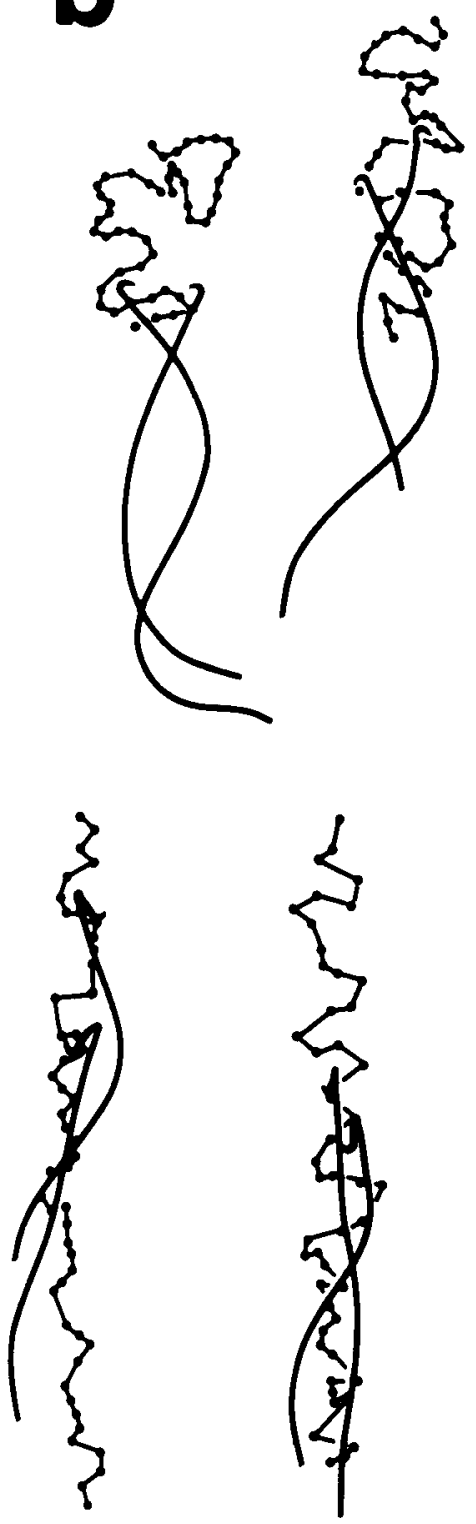

PLATE VI

Successive positions of the head-neck junction of spermatozoa diluted in normal $B_{2}$ medium (recording time : $2 \mathrm{sec}$ ).

a. Trajectory patterns of spermatozoa from the cauda epididymidis.

b. Trajectory patterns of spermatozoa from the caput epididymidis activated in the presence of crude bovine FMP.

c. Trajectory patterns of spermatozoa from the caput epididymidis activated in the presence of calmodulin inhibitor (fluphenazin). 
uncoordinated circular wave form shown by phosphodiesterase inhibitor-activated caput spermatozoa, and that the latter have not het fully developed the ability to exclude calcium ion. So, the role of FMP in the regulation of calcium transport may be to transform an anarchic movement into a progressive movement. According to this view, we tested the action of a calmodulin inhibitor, fluphenazin, on caffeine-activated spermatozoa. According to Klee et al. (1980), the binding of fluphenazin to calmodulin decreases the affinity of cell sites for $\mathrm{Ca}^{++}$and mimicks an intracellular drop in $\mathrm{Ca}^{++}$concentration. The induction of $15 \%$ of progressive spermatozoa with trajectories similar to those observed in caudal spermatozoa induced by fluphenazin suggests that the evolution of an irregular movement, limited to a confined space, into a progressive movement would require a decrease in intracellular $\mathrm{Ca}^{+}+$. FMP would decrease the high level of intracellular $\mathrm{Ca}^{++}$of activated spermatozoa to a level compatible with coordinated movement. However, the fluphenazin did not remove the flagellar angulation, suggesting that the permeability of the plasma membrane was not modified and that fluphenazin acted only on the calmodulin- $\mathrm{Ca}^{++}$complex. In the same manner, the maintenance of agglutinates is explained by the absence of some coating proteins in the incubation medium.

In conclusion, these results suggest that during epididymal maturation FMP would act by modifying membrane permeability and causing a variation in the concentration of intracellular $\mathrm{Ca}^{+}+$which may be involved in the transformation of an irregular movement into a progressive movement.

Reçu en juin 1983.

Accepté en octobre 1983.

Acknowledgements. - We are indebted to Michel Gouzy for technical assistance and to Christine Asseline for preparing the manuscript.

Résumé. Rôles de la " Forward Motility Protein " (FMP) et d'un inhibiteur de la calmoduline dans l'induction de la mobilité des spermatozoïdes de la tête de l'épididyme chez le Hamster.

Des spermatozoïdes de Hamster prélevés dans la tête de l'épididyme sont observés soit au microscope à contraste de phase ou interférentiel, soit par microcinématographie afin d'analyser leur comportement et le type de mouvement qu'ils présentent dans les conditions décrites ci-dessous. Après dilution dans le milieu $B_{2}$, la majorité des spermatozoïdes s'agglutine par la tête et leurs flagelles montrent des torsions au niveau de la pièce intermédiaire. Seule, une petite partie de la population est mobile mais le type de mouvement est anarchique. L'addition de la " forward motility protein " (FMP) d'origine bovine sous forme non purifiée au milieu $B_{2}$ supprime les angulations flagellaires et les agglutinations. L'addition de la FMP à des spermatozoïdes de la tête de l'épididyme préalablement activés par de la caféine permet d'induire chez $10 \%$ d'entre eux un mouvement progressif plus lent que celui observé dans la queue de l'épididyme.

Afin de montrer si la FMP pourrait jouer un rôle dans la régulation du transport de calcium, un inhibiteur de la calmoduline, la fluphénazine $\left(10^{-5} \mathrm{M}\right)$ a été également utilisé. Ajouté à des spermatozoïdes activés par la caféine, cet inhibiteur permet d'induire chez environ $15 \%$ d'entre eux un mouvement progressif. Toutefois, les spermatozoïdes présentent les angulations de la pièce intermédiaire mais leurs trajectoires sont comparables à celles observées à partir de spermatozoïdes issus de la queue de l'épididyme. 
Ces résultats sembleraient montrer que le passage du mouvement anarchique des spermatozoïdes immatures à un mouvement progressif ferait intervenir des mécanismes dépendants du calcium.

\section{References}

ACOTT T. S., HOSKINS D. D., 1978. Bovine sperm forward motility protein : partial purification and characterization. J. biol. Chem., 253, 6744-6750.

ACOTT T. S., HOSKINS D. D., 1981. Bovine sperm forward motility protein : binding to epididymal spermatozoa. Biol, Reprod., 24, 234-240.

ACOTT T. S., HOSKINS D. D., 1983. Cinematographic analysis of bovine epididymal sperm motility : epididymal maturation and forward motility protein. J. submicrosc. Cytol., 15, 77-82.

AMANN R. P., HAY S. R., HAMMERSTEDT R. H., 1982. Yield, characteristics, motility and cAMP content of sperm isolated from seven regions of ram epididymis. Biol. Reprod., 27, 723-733.

BLANDAU R. J., RUMERY R. E., 1964. The relationship of swimming movements of epididymal spermatozoa to their fertilizing capacity. Fertil. Steril., 15, 571-579.

DACHEUX J. L., PAQUIGNON M., COMBARNOUS Y., 1983. Head-to-head agglutination of ram and boar epididymal spermatozoa and evidence for an epididymal antagglutinin. J. Reprod. Fert., 67, 181-189.

FRAY C. S., HOFFER A. P., FAWCETT D. W., 1972. A reexamination of motility patterns of rat epididymal spermatozoa. Anat. Rec., 173, 301-308.

HAMMERSTEDT R. H., KEITH A. D., HAY S., DE LUCA N., AMANN R. P., 1979. Changes in ram sperm membranes during epididymal transit. Arch. Biochem. Biophys., 196, 7-12.

HOSKINS D. D., 1982. Epididymal development of sperm motility. Int. Conf. Development and function in cilia and sperm flagella, Siena, Italy (Abstr.).

HOSKINS D. D., ACOTT T. S., CRITCHLOW L., VIJAYARAGHAVAN S., 1983. Studies on the roles of cyclic AMP and calcium in the development of bovine sperm motility. J. submicrosc. Cytol., 15, 21-27.

HOSKINS D. D., BRANDT H., ACOTT T. S., 1978. Initiation of sperm motility in the mammalian epididymis. Fed. Proc., 37, 2534-2542.

JOHNSON A. L., HOWARDS S. S., 1977. Hyperosmolality in intraluminal fluids from hamster testis and epididymis : a micropuncture study. Science, 195, 492-493.

KANN M. L., SERRES C., 1980. Development and initiation of sperm motility in the hamster epididymis. Reprod. Nutr. Dévelop., 20, 1739-1749.

KLEE C. B., CROUGH T. H., RICHMAN P. G., 1980. Calmodulin. Ann. Rev. Biochem., 49, 489-515.

MÉNÉZO Y., 1976. Milieu synthétique pour la survie et la maturation des gamètes et pour la culture de l'œuf fécondé. C. R. Acad. Sci. Paris, Sér. D., 282, 1967-1970.

MORTON B. E., SAGADRACA R. FRASER C., 1978. Sperm motility within the mammalian epididymis : species variation and correlation with free calcium levels in epididymal plasma. Fert. Steril., 29, 695-698.

NICOLSON G. L., BRODGINSKI A. B., BEATTIE G., YANAGIMACHI R., 1979. Cell surface changes in the proteins of rabbit spermatozoa during epididymal passage. Gamete Res., 2. 153-162.

STEPHENS T. D.; ACOTT T. S., HOSKINS D. D., 1981. A cautionary note on the determination of forward motility protein activity with bovine epididymal spermatozoa. Biol. Reprod., 25, 945-949.

WYKER R., HOWARDS S. S., 1977. Micropuncture studies of the motility of rete testis and epididymal spermatozoa. Fertil. Steril., 28, 108-112. 